\title{
Robust, spatially scanning, open-path TDLAS hygrometer using retro-reflective foils for fast tomographic 2-D water vapor concentration field measurements
}

\author{
A. Seidel ${ }^{1}$, S. Wagner ${ }^{2}$, A. Dreizler ${ }^{1}$, and V. Ebert $^{1,3}$ \\ ${ }^{1}$ Department of Reactive Flows and Diagnostics, Technische Universität Darmstadt, Darmstadt, Germany \\ ${ }^{2}$ High Temperature Process Diagnostics, Technische Universität Darmstadt, Darmstadt, Germany \\ ${ }^{3}$ Physikalisch-Technische Bundesanstalt, Bundesallee 100, 38116 Braunschweig, Germany
}

Correspondence to: V. Ebert (volker.ebert@ ptb.de)

Received: 31 July 2014 - Published in Atmos. Meas. Tech. Discuss.: 20 December 2014

Revised: 17 March 2015 - Accepted: 28 March 2015 - Published: 18 May 2015

\begin{abstract}
We have developed a fast, spatially scanning direct tunable diode laser absorption spectrometer (dTDLAS) that combines four polygon-mirror based scanning units with low-cost retro-reflective foils. With this instrument, tomographic measurements of absolute 2-D water vapor concentration profiles are possible without any calibration using a reference gas.

A spatial area of $0.8 \mathrm{~m} \times 0.8 \mathrm{~m}$ was covered, which allows for application in soil physics, where greenhouse gas emission from certain soil structures shall be monitored. The whole concentration field was measured with up to $2.5 \mathrm{~Hz}$. In this paper, we present the setup and spectroscopic performance of the instrument regarding the influence of the polygon rotation speed and mode on the absorption signal. Homogeneous $\mathrm{H}_{2} \mathrm{O}$ distributions were measured and compared to a single channel, bi-static reference TDLAS spectrometer for validation of the instrument. Good accuracy and precision with errors of less than $6 \%$ of the absolute concentration and length and bandwidth normalized detection limits of up to $1.1 \mathrm{ppmv} \cdot \mathrm{m}(\mathrm{Hz})^{-0.5}$ were achieved.

The spectrometer is a robust and easy to set up instrument for tomographic reconstructions of 2-D-concentration fields that can be considered as a good basis for future field measurements in environmental research.
\end{abstract}

\section{Introduction}

In many applications in science and engineering, the spatial distribution of gas concentrations is of high interest. A highly topical example comes from environmental science: as the permafrost in arctic regions is gradually thawing, gases that affect the climate effect, such as methane, carbon dioxide or water vapor, are emitted from the soil (Anisimov and Nelson, 1997; Nakano et al., 2000; O'Connor et al., 2010; Schuur, 2009; Vonk et al., 2012; Zimov et al., 2006). This process is suspected to lead to a positive feedback on the greenhouse effect, which would increase the soil emissions even further (Field et al., 2007; Heimann and Reichstein, 2008; Luke and Cox, 2011; Olefeldt et al., 2013; Schuur, 2009). Although it is already known that such gases are released, there is, as of yet, little information on their absolute concentrations (O'Connor et al., 2010; Schuur, 2009; Schuur and Abbott, 2011; Vonk et al., 2012).

Additionally, they not only have to be quantified, but they have to be related to certain soil structures. For instance, it is presumed that greenhouse gases emanate from subterranean reservoirs through cracks in the ground (Lopez et al., 2008; Schuur and Abbott, 2011; Walter et al., 2012; Zimov et al., 2006). Taking, e.g., a picture of the ground and comparing it to the spatial distribution of gas concentration in that area is a possibility for identifying most relevant structures in soil emission.

Any instrumentation that shall be used for such field applications needs to fulfil certain requirements: first of all, the equipment has to be kept as simple as possible to reduce transport issues. At the same time, spatial resolution needs to be suitable. Alignment effort should be minimized and robustness against harsh environmental conditions needs to be ensured. In the special case of permafrost monitoring, 
measurement areas of at least $0.5 \mathrm{~m}$ edge length to several meters have to be covered. Moreover, fast 2-D-concentration field recording rates of at least $1 \mathrm{~Hz}$ are necessary for 2-D flux measurements, which could be obtained in combination with velocity measurement techniques (vertical and horizontal wind velocity).

Existing soil emission instruments have certain disadvantages if used for this type of measurement. There are instruments for gas concentration measurements (Babilotte et al., 2010; Crosson, 2008; McManus et al., 2008) or even flux measurements (McDermitt et al., 2011; Hendriks et al., 2008; Tuzson et al., 2010) that are well-suited for field applications but that do not provide a 2-D-concentration distribution. Certain variants of direct TDLAS (tunable diode laser absorption spectroscopy) are powerful techniques for field applications, as no reference gas measurement is needed for calibration (Buchholz et al., 2014) they are based on robust, industrially available components. For receiving spatially resolved concentration fields from line-of-sight data, multiple measurement paths have to be combined into a tomographic setup.

The most straight-forward way to do this is to arrange several laser sources around the field of measurement, while detectors are positioned at the opposite side. These setups allow for very fast measurements, since all channels can be recorded simultaneously and the field measurement rate equals the rate at which the concentrations along each projection are measured. However, such highly parallel, bi-static setups either require large amounts of light-source-detectorpairs and the appertaining data acquisition channels (Wright et al., 2005; Terzija et al., 2008; Terzija and McCann, 2011; Ma et al., 2013) or are somewhat limited regarding spatial resolution (Ma et al., 2009; Deguchi, 2012). Additionally, a disadvantage of bi-static setups in field applications is the cumbersome alignment of many detectors. Another well-established method for tomographic absorption measurements is the step-wise movement of the measurement object, such that several line integrals can be measured with a single bi-static channel (Liu et al., 2013; Song et al., 2013). This technique is of course not applicable for immobile measurement objects such as soil sections.

The most promising solutions are realized by sequentially moving the laser beam in some way. Kasyutich and Martin (2011) have developed a tunable laser absorption spectrometer with minimal amount of equipment and at the same time relatively high spatial resolution. Although there is only one measurement channel, multiple beams can be evaluated consecutively. This is facilitated by two mirrors for fanbeam scanning that are moved by carriages along a circular rail. However, the sequential scanning measurement of the whole field takes about $160 \mathrm{~s}$, so the instrument is only suited for stationary conditions. Wang et al. (2010), by contrast, present an instrument that continuously rotates laser beams at four different positions across the field. Thus it is very fast (100 ms per field scan) and nevertheless has reduced complexity: due to retro-reflecting mirrors on the opposite field side, only one detector per scanner is necessary. The angle of the fan-beam cone amounts to $11^{\circ}$ because of the mirror size $(15 \mathrm{~cm} \times 5 \mathrm{~cm})$ : only in this small area the retro-reflectors are hit. While the small scan angle is no limitation in their application, unfortunately it is a huge drawback for the environmental measurements. Wang et al.(2010) were able to draw the system boundary of their measurements in a way that the whole field is more or less covered with laser beams because they did obviously not expect any absorption outside of this target region. In contrast to this, in the environmental application the absorbing medium may be everywhere, and small fan-beam angles therefore lead to small measurement field coverages.

In this paper, we present a tomographic absorption spectrometer that consists of four fan-beam scanners. Instrumentation effort is minimized with a setup that contains combined emitting and detecting units and very inexpensive retro-reflective foils as reflecting targets. The basic principle of a single-channel foil TDLAS instrument has been described in a previous publication (Seidel et al., 2012). This static instrument has now been expanded to a spatially scanning 2-D-spectrometer. Due to the retro-reflecting foils, the instrument is very easy to align. Furthermore, many absorption paths of wide-angled fan beams are realized, attaining a good spatial coverage of the measurement field. Tomographic reconstruction based on Tikhonov or Bayesian algorithm can be applied to the measured data to calculate the 2D- $\mathrm{H}_{2} \mathrm{O}$-distribution. Discussion of tomographic reconstruction, however, is not within the focus of this publication.

In the following, we provide a detailed description of the 2-D-TDLAS fan-beam instrument and its performance compared to a static path-averaged measurement. In Sect. 2, we briefly explain the measurement method TDLAS that is used for the single-channel concentration measurements. Afterwards we present the setup of the instrument (Sect. 3) and elaborate on first $\mathrm{H}_{2} \mathrm{O}$ vapor validation measurements of a homogenous 2-D-concentration field (Sect. 4).

\section{Measurement method}

Direct tunable diode laser absorption spectroscopy (dTDLAS) is a favorable method for field measurements for various reasons: first of all, it can provide absolute gas concentrations without the need for any reference gas measurements (Buchholz et al., 2014). Besides, the technical components are industrially available and easily transportable. Diode lasers are very compact and fiber-coupling simplifies the handling in the field. Direct TDLAS is based on Lambert-Beer's law, of which we use an extended version to deal with non-specific absorption and broadband light losses (Ebert, 2011a; Schulz, 2007a):

$$
n=-\frac{1}{S(T) \cdot l} \cdot \int \ln \left(\frac{I(n, \lambda)-E(t)}{I_{0}(\lambda) \cdot \operatorname{Tr}(t)}\right) \frac{\partial \lambda}{\partial t} \mathrm{~d} t,
$$




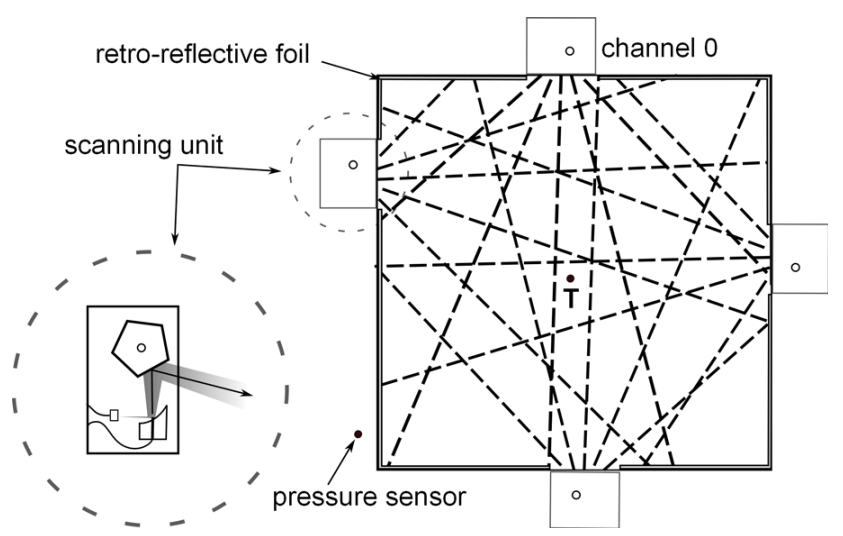

Figure 1. Schematic drawing of the tomographic setup (top view). Four scanning units are placed on the edges of a $0.8 \mathrm{~m} \times 0.8 \mathrm{~m}$ measurement field. The circumference of the remaining area is covered with low-cost retro-reflecting tape. Some exemplary laser beams are depicted as dashed lines. A schematic illustration of the scanning unit contents is shown in the detail circle. The components are described in Sect. 3. Temperature sensor $(\mathrm{T})$ was placed in the middle of the area while the pressure sensor measures the room pressure in a distance of about $0.3 \mathrm{~m}$.

where $I_{0}(\lambda)$ is the incident light emitted by a diode laser that is periodically tuned across a molecular absorption line. After passing through the absorbing medium, where a wavelength-depending attenuation takes place, the intensity $I(n, \lambda)$ is detected. The exponential relationship between detected and incident light depends on temperature-depending line strength $S(T)$, a pressure- and temperature-dependent absorption line shape described by $\Phi\left(\lambda-\lambda_{0}\right)$, the absorber number density $n$ and the absorption path length $l$. In addition to that, background radiation $E(t)$ and transmission losses $\operatorname{Tr}(t)$ are considered. With known absorption path length, dynamic wavelength tuning characteristic $\frac{\partial \lambda}{\partial t}$ and gas temperature $T, n$ can be derived from

$\mathrm{OD}_{\mathrm{e}}=-\ln \left(\frac{I(n, \lambda)-E}{I_{0}(n, \lambda) \cdot \operatorname{Tr}(\lambda)}\right)$.

The absorber volume concentration (expressed in ppmv) is then calculated via the ideal gas law, as temperature and pressure are known. This version of direct TDLAS has been presented for numerous applications, e.g., biological (Hunsmann et al., 2008; Wunderle et al., 2009), engineering (Ortwein et al., 2010; Wagner et al., 2009; Teichert et al., 2003), or atmospheric research (Buchholz et al., 2013).

\section{TDLAS tomography hardware}

The presented tomographic spectrometer consists of four scanning units that are located of a $0.8 \mathrm{~m} \times 0.8 \mathrm{~m}$ measurement field (view Fig. 1). The near the corners rest of the field edges are covered with retro-reflective foil (Seidel et al., 2012), so that many reflected beams can be detected. The scanning units comprise the emitting as well as the detecting optics. All optical components are included in a closed box that can be purged with, e.g., dry air or nitrogen and that protects the optics from the environment. Each of the units is connected to a 1-to-4 fiber-beam-splitter that receives light from a $1370 \mathrm{~nm}$ DFB-laser (Distributed Feeback Laser). Inside the box, the light is emitted by a fiber-coupled grin lens with a diameter of approximately $1 \mathrm{~mm}$ that is placed in a hole drilled into the center of an off-axis parabolic mirror. Afterwards, the light is guided onto a rotating polygon mirror with five facets. It passes a wedged window and enters the measurement field, where it is retro-reflected at the opposite side by the foil. It re-enters the box through the window, is reflected at the rotating polygon mirror and focused onto a $1 \mathrm{~mm}$ diameter, uncooled indium gallium arsenide ( $\mathrm{InGaAs}$ ) detector by the off-axis parabolic mirror. As the polygon is rotated continuously by a stepper motor, the beam is scanned horizontally across the measurement area. Overall, the laser beams cover more than $75 \%$ of the measurement field area. The absorption pathlength was calculated based on the geometry of the setup and the absolute angular position of the stepper motor.

We compared the measurement quality of the 2-D scanning instrument to a stationary, non-scanning reference TDLAS setup (view Fig. 2). For this purpose we used a bi-static setup: light from a fiber-coupled DFB laser at $1370 \mathrm{~nm}$ is collimated by a collimator. After passing an absorption path of $700 \mathrm{~mm}$ length, it is detected by an InGaAs detector. All other processing steps are identical to the previous tomographic system. Below, we shortly describe details regarding the retro-reflecting foils (Sect. 3.1), the scanning system (Sect. 3.2) and the data acquisition (Sect. 3.3).

\subsection{Retroreflecting foils}

Instead of a costly system with many light sources, detectors and mirrors, we use a setup with retro-reflecting foil. This foil enables us to detect hundreds of beams with only four data acquisition channels by scanning the beam across the area. Usually, such foils are used for safety and traffic applications, which makes them industrially available and inexpensive. They reflect light like a retro-reflector even for long distances and large impact angles, such that incident beams at the edges of the fan-beam cone can also be used. An elaborate presentation of the foil reflection characteristics and static water vapor measurements is discussed in a previous paper (Seidel et al., 2012).

\subsection{Polygon scanning unit}

The laser beams are spatially scanned by rotating polygon mirrors. Four stepper motors are rotated continuously and their positions are recorded by TTL signals (transistortransistor logic) of the motor drivers, such that the angles of the laser beams are known. At the same time, the laser is 


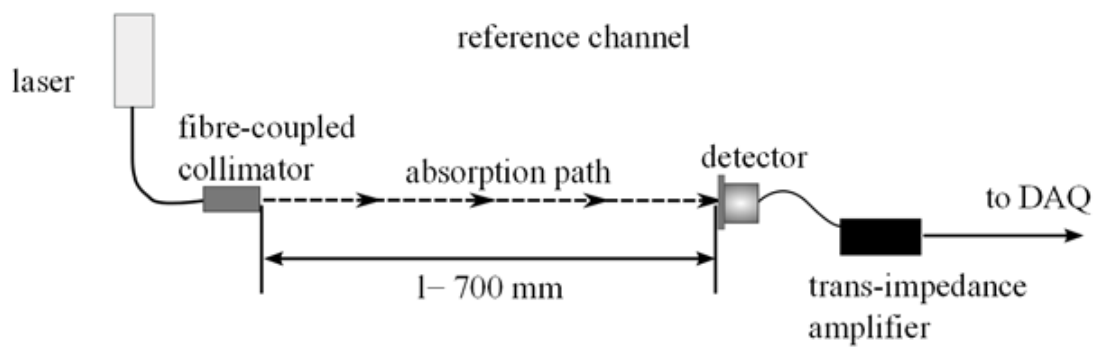

Figure 2. Static TDLAS spectrometer setup for reference measurements of the $\mathrm{H}_{2} \mathrm{O}$ concentration.

tuned with $5039.8 \mathrm{~Hz}$ repetition rate across the $\mathrm{H}_{2} \mathrm{O}$ absorption line. Depending on the polygon rotation speed, the beam moves by a certain fraction of a degree on the retro-reflecting foil during one concentration measurement. Different rotation speeds have been realized and checked for suitability (view Sect. 4). Every scanner has a polygonal mirror with five facets, which results in a total scanning angle of $144^{\circ}$. The laser beam at $18.5^{\circ}$ is used as a reference for the absolute position once in the beginning of the measurement. As long as the motors are supplied with voltage, the position does not have to be re-calibrated since the relative position is recorded during the motor movement.

\subsection{Data acquisition and laser light source}

A fiber-coupled DFB-laser at $1370 \mathrm{~nm}$ with a current tuning range of about $2 \mathrm{~cm}^{-1}$ is modulated over the $211 \leftarrow 110 \mathrm{H}_{2} \mathrm{O}$ absorption line at $7299.43 \mathrm{~cm}^{-1}$ (Hunsmann et al., 2008; Buchholz et al., 2014). For this purpose, a function generator produced a triangular current modulation signal. To achieve as many beam paths as possible with a high field measurement rate, we set the laser tuning rate to $5 \mathrm{kHz}$. All four TDLAS signals were recorded with $10 \mathrm{MS} \mathrm{s}^{-1}$ and 14 bit resolution. At the same time, the scanning position TTL signal, ambient pressure and temperature are recorded. Position signal and pressure were measured with $129 \mathrm{kS} \mathrm{s}^{-1}$ and 18 bit each. A barometric pressure sensor with an accuracy of $0.3 \mathrm{hPa}$ was used. Temperature was measured with a type E thermocouple ( $1.5 \mathrm{~K}$ accuracy) with 100 Samples/s and 18 bit. All signals were triggered once by the master trigger coming from the signal generator and then measured continuously. For evaluation, the start of the TDLAS tuning ramp has to be known. As we measured continuously for speed reasons, we needed a time reference on the TDLAS signal itself since the time base precision of the PXI rack (PCI bus protocol eXtensions for Instrumentation) proved to be insufficient. Therefore, we added a pulse from a pulse generator onto the TDLAS signal and split the data during post-processing by an edge-detection algorithm. For evaluation of the TDLAS measurements, we used an in-house LabVIEW software.

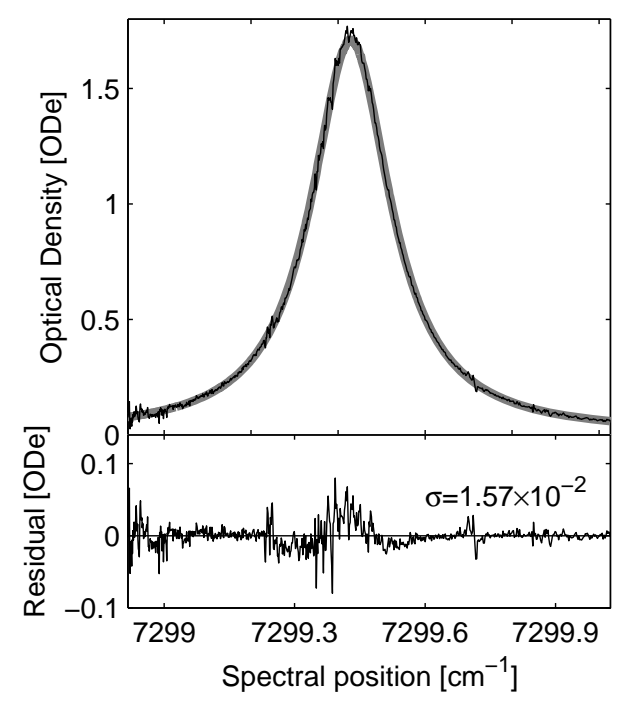

Figure 3. Top: Measured and fitted $\mathrm{H}_{2} \mathrm{O}$ vapor absorption signal (unaveraged) while continuously spatially scanning the laser beam at $1.25 \mathrm{~Hz}$ field measurement rate. The laser wavelength tuning rate amounted $5039.8 \mathrm{~Hz}$. Bottom: residual between fit and measured signal. Concentration amounted $12038 \mathrm{ppmv}$ at an absorption path length of $1.98 \mathrm{~m}$, temperature of $293.5 \mathrm{~K}$ and pressure of $995 \mathrm{mbar}$.

\section{TDLAS measurements}

By measuring the uniform $\mathrm{H}_{2} \mathrm{O}$ vapor concentration distribution of the surrounding atmosphere and comparing it to a static reference channel, the performance of the instrument regarding accuracy and precision was examined. We tested two different motor velocities (30 and $15 \mathrm{rpm}$ ) as well as a step-wise vs. continuous polygon movement (only Channel 0 ) and studied the influence of rotation on the TDLAS measurement. For the continuously moved motors, velocities correspond to measurement rates of the whole field of 2.5 and $1.25 \mathrm{~Hz}$, respectively. The duration of the step-wise movement of the whole field was in the range of a few minutes. Overall, we evaluated more than 360 different beams during continuous scanning. In the step-wise case, the motor was moved in steps of $1.44^{\circ}$, which leads to 100 steps per facet. At some angles, reflection is poor because of large light incidence angles on the foil, and if the laser beam hits 
an opposite scanning unit, reflection completely disappears. For this reason, only 44 beams where evaluated for Channel 0 during the step-wise measurement.

In all cases, the $\mathrm{H}_{2} \mathrm{O}$ absorber number densities were determined by fitting a third order polynomial to the baseline of the raw signal and fitting Voigt profiles with 19 lines between 7294.12 and $7306.75 \mathrm{~cm}^{-1}$ to the absorption signal. For this, we used spectral line data from the HITRAN 2012 database (Rothman et al., 2013).

Figure 3 displays a representative example of the measured and fitted absorption profile that was achieved while scanning continuously at $1.25 \mathrm{~Hz}$ field scan rate. No averaging was applied here, so the time resolution was approximately $0.2 \mathrm{~ms}$. In this case, the overall standard deviation of the residual $(1 \sigma)$ that was attained at $12038 \mathrm{ppmv}^{\mathrm{H}} \mathrm{O}$ is $1.57 \times 10^{-2} \mathrm{OD}_{\mathrm{e}}$. The optical density is defined as

$\mathrm{OD}_{\mathrm{e}}=-\ln \left(\frac{I(n, \lambda)-E}{I_{0}(n, \lambda) \cdot \operatorname{Tr}(\lambda)}\right)$.

The noise on the signal is dominated by electrical disturbances caused by the electric stray field of the stepper motors. A signal to noise of 108 was calculated by the ratio between the peak absorption and the standard deviation of the residual. With an absorption length of $1.98 \mathrm{~m}$, the normalized detection limit is $3.1 \mathrm{ppmv} \cdot \mathrm{m}(\mathrm{Hz})^{-0.5}$. Depending on the position of the laser beam and the rotation speed of the motor, we achieved signal to noise ratios of up to 224 and hence detection limits of up to $1.1 \mathrm{ppmv} \cdot \mathrm{m}(\mathrm{Hz})^{-0.5}$.

An overview of typical concentration measurements while continuously scanning is given in Fig. 4. In the left column, all four fan-beam units, represented by channels $0-3$, are shown for a 2-D field measurement rate of $2.5 \mathrm{~Hz}$; the same is shown in the right column for $1.25 \mathrm{~Hz}$. For all cases, the $\mathrm{H}_{2} \mathrm{O}$ concentration was plotted for all angles in a fan-beam, while the reference concentration is plotted as a solid line. Precision is enhanced when it is scanned slower, presumably because transmission and absorption length variation during one wavelength tune decrease.

A full listing of scanning measurement performance is shown in Table 1. The average concentrations measured in each channel during continuous scanning, $\bar{c}_{\text {Scan }}$, range from about 11950-12380 ppmv. The average measured concentration when scanning at $2.5 \mathrm{~Hz}$ image rate amounted to 12048 , and $12176 \mathrm{ppmv}$ when scanning at $1.25 \mathrm{~Hz}$. At the same time, a reference concentration with an average of $\bar{c}_{\text {Ref }}=12548 \mathrm{ppmv}$ and a standard deviation of about 9 ppmv was measured with the static setup depicted in Fig. 2. The standard deviation is an indicator for precision, not for accuracy, which is expected to be in the order of magnitude of less than $5 \%$ (Fahey et al., 2014). The concentration standard deviation in one channel ranges from about 380 750 ppmv, which corresponds to a relative standard deviation of 3 and $6 \%$ of the average concentration. Furthermore, we have calculated the deviations of the averaged concentrations from the reference measurement $\left(\bar{c}_{\text {Scan }}-\bar{c}_{\text {Ref }}\right)$. All

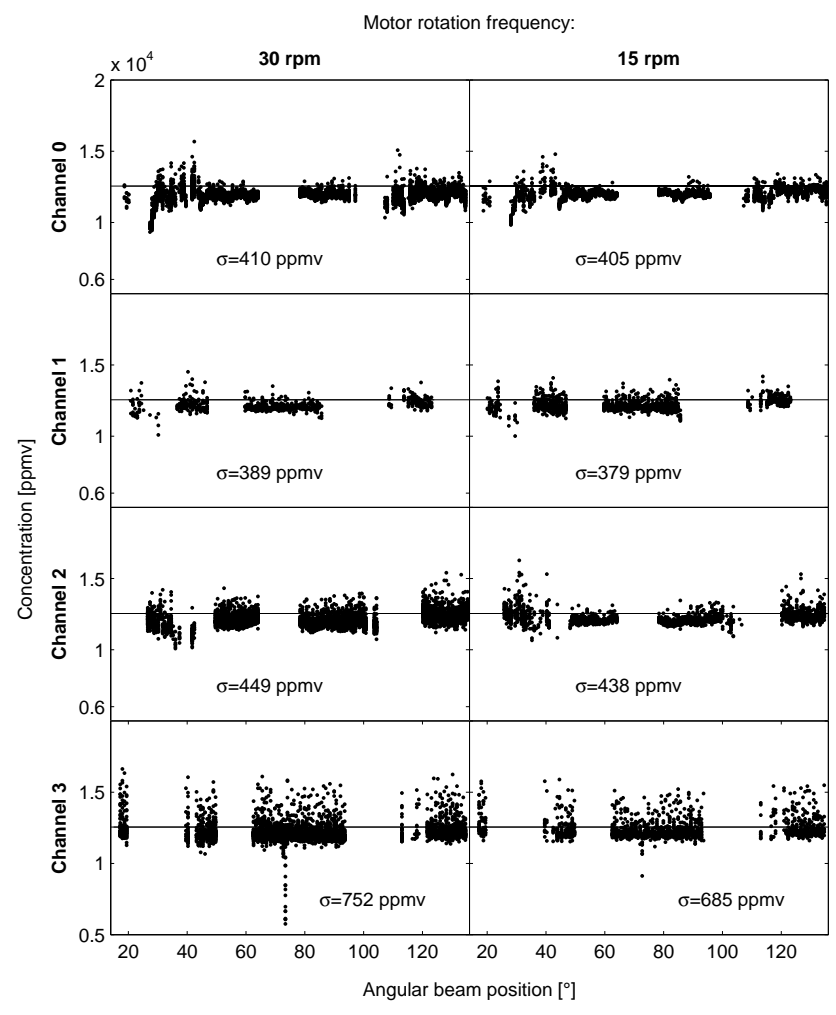

Figure 4. $\mathrm{H}_{2} \mathrm{O}$ concentrations measured with continuously scanning spectrometer for different polygon mirror rotation speeds. Channel 0 to Channel 3 depict the four scanning/receiver units. In the left column, results are shown that were recorded at $30 \mathrm{rpm}$ motor rotation frequency, which leads to a 2-D- $\mathrm{H}_{2} \mathrm{O}$-field rate of $2.5 \mathrm{~Hz}$. In the right column, the motor rotation frequency amounted $15 \mathrm{rpm}$, corresponding to $1.25 \mathrm{~Hz}$ field rate. The solid lines show the average $\mathrm{H}_{2} \mathrm{O}$ concentration measured with the bi-static TDLAS reference spectrometer $\left(\bar{c}_{\text {Ref }}\right)$. At some angular positions, no evaluation of the detected signal could take place. This is due to very poor reflection of the laser light while the beam is moving across opposite scanning units or in instances when the light incidence angle onto the foil is too large.

concentration channels underestimate the reference concentration by about $170-597 \mathrm{ppmv}$, which corresponds to 1.3 $4.8 \%$ of the absolute concentration. Although this bias lies within the measurement uncertainty of the static reference instrument (Buchholz et al., 2013), the systematically negative deviation of the scanning measurement should be kept in mind and evaluated further.

We also compared the continuous scanning mode to stepwise measurements, where the motor is sequentially moved but stopped for measuring the absorption signal. The overall time for scanning the whole field step-wise took more than four minutes. Results are shown in Fig. 5 and listed in detail in Table 1. Note that the reference concentration is higher than during the scanning measurements, since the step-wise measurement took place a few days later. The standard deviation of the $\mathrm{H}_{2} \mathrm{O}$-concentration is in the order of magnitude 
Table 1. $\mathrm{H}_{2} \mathrm{O}$ concentration performance of the scanning measurements compared with a static reference measurement and a step-wise scanning measurement.

\begin{tabular}{lcccccc}
\hline & Channel & $\bar{c}_{\text {Scan }}(\mathrm{ppm})$ & $\sigma_{c, \text { Scan }}(\mathrm{ppm})$ & $\bar{c}_{\text {Scan }}-\bar{c}_{\text {Ref }}$ & $\sigma_{c, \text { Scan }}(\%)$ & $\bar{c}_{\text {Scan }}-\bar{c}_{\text {Ref }}(\%)$ \\
\hline $2.5 \mathrm{~Hz}$ & 0 & 11951.1 & 410.3 & -597.0 & 3.3 & -4.8 \\
& 1 & 12100.8 & 389.4 & -447.3 & 3.1 & -3.6 \\
& 2 & 12033.6 & 448.6 & -514.6 & 3.6 & -4.1 \\
& 3 & 12051.9 & 752.4 & -496.3 & 6.0 & -4.0 \\
\hline $1.25 \mathrm{~Hz}$ & 0 & 12028.7 & 405.1 & -519.4 & 3.2 & -4.1 \\
& 1 & 12087.7 & 379.1 & -460.4 & 3.0 & -3.7 \\
& 2 & 12122.0 & 437.6 & -426.1 & 3.5 & -3.4 \\
& 3 & 12159.1 & 684.7 & -389.0 & 5.5 & -3.1 \\
\hline \multirow{2}{*}{ step-wise } & 0 & 14231.5 & 475.9 & -220.7 & 3.3 & -1.5 \\
\hline
\end{tabular}

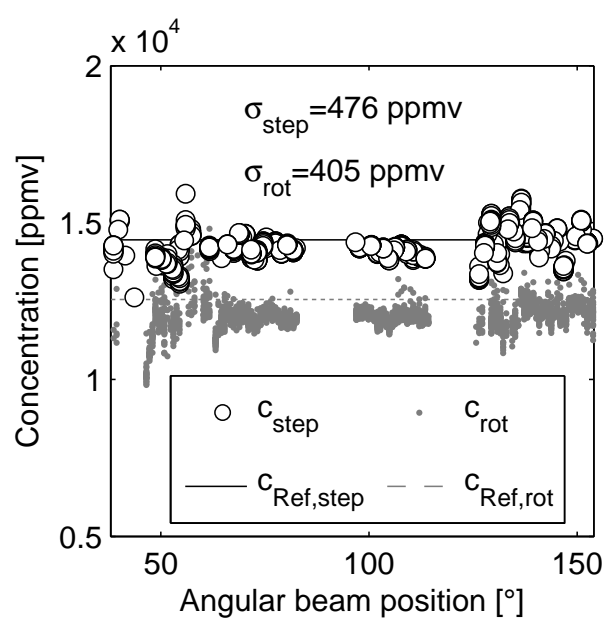

Figure 5. $\mathrm{H}_{2} \mathrm{O}$-measurement with step-wise scanned laser beam $\left(c_{\text {step }}\right)$ compared to the measurement with continuously moved laser beam $\left(c_{\text {rot }}\right.$, field rate $1.25 \mathrm{~Hz}$ ). The lines depict the average reference $\mathrm{H}_{2} \mathrm{O}$-concentrations, respectively.

of the standard deviation that was achieved with the continuously scanning measurement. However, the systematic deviation from the reference measurement is slightly smaller. Since the beam is not moved during the absorption measurement, there is no variation of absorption length and hardly any transmission variation during one tuning run. This may be the reason for the better accuracy of the step-wise measurement compared to the scanning channel, in which there are more likely to be inaccuracies in the absorption pathlength. Preliminary numerical simulations were carried out, confirming that tomographic measurements with noise in the achieved order of magnitude are possible.

The accomplished field measurement rate of $2.5 \mathrm{~Hz}$ can be increased further by raising the laser tuning rate, e.g., by using a VCSEL (vertical cavity surface emitting laser) instead of a DFB laser. With a VCSEL, tuning repetition rates of $30 \mathrm{kHz}$ or more are realistic (Witzel et al., 2013), corresponding to up to $15 \mathrm{~Hz}$ field measurement rate.

\section{Conclusions}

We have presented a TDLAS spectrometer for spatially resolved 2-D-concentration measurements that may serve as a prototype for permafrost field measurements. Besides covering a relatively large measurement area of $0.8 \mathrm{~m} \times 0.8 \mathrm{~m}$, it achieves rather fast field measurement rates of up to $2.5 \mathrm{~Hz}$. A high number of usable laser beams (>350) and a relative field coverage of more than $75 \%$ are favorable regarding tomographic spatial resolution. Measurements of homogeneous $\mathrm{H}_{2} \mathrm{O}$ distributions prove that accuracy and precision are satisfying regarding tomographic reconstructions. Relative standard deviations of the path-averaged concentrations amounted to 3 and $6 \%$, whereas the relative systematic deviations to a reference measurement amounted to 1.3 and $4.8 \%$. In the future, the field measurement rate can be increased by raising the tuning rate of the laser, which requires replacement of the DFB laser by a VCSEL laser. We aim to carry out tomographic measurements and reconstructions with known concentration distributions for validation and later on measure first 2-D-concentration fields above soils. Other molecules, such as $\mathrm{CH}_{4}$, shall also be quantified. As static measurements with distances of more than $5 \mathrm{~m}$ between the emitting side and the retro-reflective foil have been successfully realized (Seidel et al., 2012), scanning experiments covering larger areas seem possible and are planned.

Acknowledgements. This project was funded by the Deutsche Forschungsgemeinschaft (DFG) within the postgraduate program GRK1114.

Edited by: T. F. Hanisco 


\section{References}

Anisimov, O. A. and Nelson, F. E.: Permafrost Zonation And Climate Change In The Northern Hemisphere: Results From Transient General Circulation Models, Clim. Change, 35, 241-258, doi:10.1023/A:1005315409698, 1997.

Babilotte, A., Lagier, T., Fiani, E., and Taramini, V.: Fugitive Methane Emissions from Landfills: Field Comparison of Five Methods on a French Landfill, J. Environ. Eng., 136, 777-784, doi:10.1061/(ASCE)EE.1943-7870.0000260, 2010.

Buchholz, B., Kühnreich, B., Smit, H. G. J., and Ebert, V.: Validation of an extractive, airborne, compact TDL spectrometer for atmospheric humidity sensing by blind intercomparison, Appl. Phys. B, 110, 249-262, doi:10.1007/s00340-012-5143-1, 2013.

Buchholz, B., Böse, N., and Ebert, V.: Absolute validation of a diode laser hygrometer via intercomparison with the German national primary water vapor standard, Appl. Phys. B, 116, 883899, doi:10.1007/s00340-014-5775-4, 2014.

Crosson, E. R.: A cavity ring-down analyzer for measuring atmospheric levels of methane, carbon dioxide, and water vapor, Appl. Phys. B, 92, 403-408, doi:10.1007/s00340-008-3135-y, 2008.

Fahey, D. W., Gao, R.-S., Möhler, O., Saathoff, H., Schiller, C., Ebert, V., Krämer, M., Peter, T., Amarouche, N., Avallone, L. M., Bauer, R., Bozóki, Z., Christensen, L. E., Davis, S. M., Durry, G., Dyroff, C., Herman, R. L., Hunsmann, S., Khaykin, S. M., Mackrodt, P., Meyer, J., Smith, J. B., Spelten, N., Troy, R. F., Vömel, H., Wagner, S., and Wienhold, F. G.: The AquaVIT-1 intercomparison of atmospheric water vapor measurement techniques, Atmos. Meas. Tech., 7, 3177-3213, doi:10.5194/amt-7-3177-2014, 2014.

Field, C. B., Lobell, D. B., Peters, H. A., and Chiariello, N. R.: Feedbacks of Terrestrial Ecosystems to Climate Change, Annu. Rev. Environ. Res., 32, 1-29, doi:10.1146/annurev.energy.32.053006.141119, 2007.

Heimann, M. and Reichstein, M.: Terrestrial ecosystem carbon dynamics and climate feedbacks, Nature, 451, 289-292, doi:10.1038/nature06591, 2008.

Hendriks, D. M. D., Dolman, A. J., van der Molen, M. K., and van Huissteden, J.: A compact and stable eddy covariance set-up for methane measurements using off-axis integrated cavity output spectroscopy, Atmos. Chem. Phys., 8, 431-443, doi:10.5194/acp-8-431-2008, 2008.

Hunsmann, S., Wunderle, K., Wagner, S., Rascher, U., Schurr, U., and Ebert, V.: Absolute, high resolution water transpiration rate measurements on single plant leaves via tunable diode laser absorption spectroscopy (TDLAS) at $1.37 \mu \mathrm{m}$, Appl. Phys. B, 92, 393-401, doi:10.1007/s00340-008-3095-2, 2008.

Kasyutich, V. L. and Martin, P. A.: Towards a two-dimensional concentration and temperature laser absorption tomography sensor system, Appl. Phys. B, 102, 149-162, doi:10.1007/s00340-0104123-6, 2011.

Liu, C., Xu, L., and Cao, Z.: Measurement of nonuniform temperature and concentration distributions by combining line-of-sight tunable diode laser absorption spectroscopy with regularization methods, Appl. Opt., 52, 4827-4842, 2013.

Lopez C., M. L., Gerasimov, E., Machimura, T., Takakai, F., Iwahana, G., Fedorov, A. N., and Fukuda, M.: Comparison of carbon and water vapor exchange of forest and grassland in permafrost regions, Central Yakutia, Russia, Agr. Forest Meteorol., 148, 1968-1977, doi:10.1016/j.agrformet.2008.09.013, 2008.
Luke, C. M. and Cox, P. M.: Soil carbon and climate change: from the Jenkinson effect to the compost-bomb instability, Eur. J. Soil Sci., 62, 5-12, doi:10.1111/j.1365-2389.2010.01312.x, 2011.

Ma, L., Cai, W., Caswell, A. W., Kraetschmer, T., Sanders, S. T., Roy, S., and Gord, J. R.: Tomographic imaging of temperature and chemical species based on hyperspectral absorption spectroscopy, Opt. Expr., 17, 8602, doi:10.1364/OE.17.008602, 2009.

Ma, L., Li, X., Sanders, S. T., Caswell, A. W., Roy, S., Plemmons, D. H., and Gord, J. R.: 50-kHz-rate 2D imaging of temperature and $\mathrm{H}_{2} \mathrm{O}$ concentration at the exhaust plane of a J85 engine using hyperspectral tomography, Opt. Expr., 21, 1152-1162, 2013.

McDermitt, D., Burba, G., Xu, L., Anderson, T., Komissarov, A., Riensche, B., Schedlbauer, J., Starr, G., Zona, D., Oechel, W., Oberbauer, S., and Hastings, S.: A new low-power, open-path instrument for measuring methane flux by eddy covariance, Appl. Phys. B, 102, 391-405, doi:10.1007/s00340-010-4307-0, 2011.

McManus, J. B., Shorter, J. H., Nelson, D. D., Zahniser, M. S., Glenn, D. E., and McGovern, R. M.: Pulsed quantum cascade laser instrument with compact design for rapid, high sensitivity measurements of trace gases in air, Appl. Phys. B, 92, 387-392, doi:10.1007/s00340-008-3129-9, 2008.

Nakano, T., Kuniyoshi, S., and Fukuda, M.: Temporal variation in methane emission from tundra wetlands in a permafrost area, northeastern Siberia, Atmos. Environ., 34, 1205-1213, doi:10.1016/S1352-2310(99)00373-8, 2000.

O'Connor, F. M., Boucher, O., Gedney, N., Jones, C. D., Folberth, G. A., Coppell, R., Friedlingstein, P., Collins, W. J., Chappellaz, J., Ridley, J., and Johnson, C. E.: Possible role of wetlands, permafrost, and methane hydrates in the methane cycle under future climate change: A review, Rev. Geophys., 48, RG4005, doi:10.1029/2010RG000326, 2010.

Olefeldt, D., Turetsky, M. R., Crill, P. M., and McGuire, A. D.: Environmental and physical controls on northern terrestrial methane emissions across permafrost zones, Glob. Change Biol., 19, 589-603, doi:10.1111/gcb.12071, 2013.

Ortwein, P., Woiwode, W., Fleck, S., Eberhard, M., Kolb, T., Wagner, S., Gisi, M., and Ebert, V.: Absolute diode laser-based in situ detection of $\mathrm{HCl}$ in gasification processes, Exp. Fluids, 49, 961-968, doi:10.1007/s00348-010-0904-2, 2010.

Rothman, L. S., Gordon, I. E., Babikov, Y., Barbe, A., Chris Benner, D., Bernath, P. F., Birk, M., Bizzocchi, L., Boudon, V., Brown, L. R., Campargue, A., Chance, K., Cohen, E. A., Coudert, L. H., Devi, V. M., Drouin, B. J., Fayt, A., Flaud, J.-M., Gamache, R. R., Harrison, J. J., Hartmann, J.-M., Hill, C., Hodges, J. T., Jacquemart, D., Jolly, A., Lamouroux, J., Le Roy, R. J., Li, G., Long, D. A., Lyulin, O. M., Mackie, C. J., Massie, S. T., Mikhailenko, S., Müller, H. S. P., Naumenko, O. V., Nikitin, A. V., Orphal, J., Perevalov, V., Perrin, A., Polovtseva, E. R., Richard, C., Smith, M. A. H., Starikova, E., Sung, K., Tashkun, S., Tennyson, J., Toon, G. C., Tyuterev, V1. G., and Wagner, G.: The HITRAN2012 molecular spectroscopic database, J. Quant. Spectrosc. Ra., 130, 4-50, doi:10.1016/j.jqsrt.2013.07.002, 2013.

Schuur, E. A. G. and Abbott, B.: Climate change: High risk of permafrost thaw, Nature, 480, 32-33, doi:10.1038/480032a, 2011.

Schuur, E. A. G., Vogel, J. G., Crummer, K. G., Lee, H., Sickman, J. O., and Osterkamp, T. E.: The effect of permafrost thaw on 
old carbon release and net carbon exchange from tundra, Nature, 459, 556-559, doi:10.1038/nature08031, 2009.

Seidel, A., Wagner, S., and Ebert, V.: TDLAS-based open-path laser hygrometer using simple reflective foils as scattering targets, Appl. Phys. B, 109, 497-504, doi:10.1007/s00340-012-5228-x, 2012.

Song, J., Hong, Y., Wang, G., and Pan, H.: Algebraic tomographic reconstruction of two-dimensional gas temperature based on tunable diode laser absorption spectroscopy, Appl. Phys. B, 112, 529-537, doi:10.1007/s00340-013-5435-0, 2013.

Teichert, H., Fernholz, T., and Ebert, V.: Simultaneous In Situ Measurement of $\mathrm{CO}, \mathrm{H}_{2} \mathrm{O}$, and Gas Temperatures in a Full-Sized Coal-Fired Power Plant by Near-Infrared Diode Lasers, Appl. Opt., 42, 2043, doi:10.1364/AO.42.002043, 2003.

Terzija, N. and McCann, H.: Wavelet-Based Image Reconstruction for Hard-Field Tomography With Severely Limited Data, IEEE Sensors J., 11, 1885-1893, doi:10.1109/JSEN.2010.2100378, 2011.

Terzija, N., Davidson, J. L., Garcia-Stewart, C. A., Wright, P., Ozanyan, K. B., Pegrum, S., Litt, T. J., and McCann, H.: Image optimization for chemical species tomography with an irregular and sparse beam array, Meas. Sci. Technol., 19, 094007, doi:10.1088/0957-0233/19/9/094007, 2008.

Tuzson, B., Hiller, R. V., Zeyer, K., Eugster, W., Neftel, A., Ammann, C., and Emmenegger, L.: Field intercomparison of two optical analyzers for $\mathrm{CH}_{4}$ eddy covariance flux measurements, Atmos. Meas. Tech., 3, 1519-1531, doi:10.5194/amt-3-1519-2010, 2010.

Vonk, J. E., Sánchez-García, L., van Dongen, B. E., Alling, V., Kosmach, D., Charkin, A., Charkin, A., Semiletov, I. P., Dudarev, O. V., Shakhova, N., Roos, P., Eglinton, T. I., Andersson, A., and Gustafsson, O.: Activation of old carbon by erosion of coastal and subsea permafrost in Arctic Siberia, Nature, 489, 137-140, doi:10.1038/nature11392, 2012.
Wagner, S., Fisher, B. T., Fleming, J. W., and Ebert, V.: TDLASbased in situ measurement of absolute acetylene concentrations in laminar 2D diffusion flames, Proc. Combust. Inst., 32, 839846, doi:10.1016/j.proci.2008.05.087, 2009.

Walter, A., Katey, M., Anthony, P., Grosse, G., and Chanton, J.: Geologic methane seeps along boundaries of Arctic permafrost thaw and melting glaciers, Nat. Geosci., 5, 419-426, doi:10.1038/ngeo1480, 2012.

Wang, F., Cen, K. F., Li, N., Jeffries, J. B., Huang, Q. X., Yan, J. H., and Chi, Y.: Two-dimensional tomography for gas concentration and temperature distributions based on tunable diode laser absorption spectroscopy, Meas. Sci. Technol. 21, 045301, doi:10.1088/0957-0233/21/4/045301, 2010.

Witzel, O., Klein, A., Meffert, C., Wagner, S., Kaiser, S., Schulz, C., and Ebert, V.: VCSEL-based, high-speed, in situ TDLAS for in-cylinder water vapor measurements in IC engines, Opt. Expr., 21, 19951-19965, 2013.

Wright, P., Garcia-Stewart, C. A., Carey, S. J., Hindle, F. P., Pegrum, S. H., Colbourne, S. M., Turner, P. J., Hurr, W. J., Litt, T. J., Murray, S. C., Crossley, S. D., Ozanyan, K. B., and McCann, H.: Toward in-cylinder absorption tomography in a production engine, Appl. Opt., 44, 6578, doi:10.1364/AO.44.006578, 2005.

Wunderle, K., Wagner, S., Pasti, I., Pieruschka, R., Rascher, U., Schurr, U., and Ebert, V.: Distributed feedback diode laser spectrometer at $27 \mu \mathrm{m}$ for sensitive, spatially resolved $\mathrm{H}_{2} \mathrm{O}$ vapor detection, Appl. Opt., 48, B172, doi:10.1364/AO.48.00B172, 2009.

Zimov, S. A., Schuur, E. A. G., and Chapin, F. S.: Climate change. Permafrost and the global carbon budget, Science, 312, 16121613, doi:10.1126/science.1128908, 2006. 